\title{
MASS TRANSFER BETWEEN GAS AND PARTICLES IN A GAS-SOLID TRICKLE FLOW REACTOR
}

\author{
J. H. A. KIEL, ${ }^{\dagger}$ W. PRINS and W. P. M. VAN SWAAIJ \\ Department of Chemical Engineering, University of Twente, P.O. Box 217, 7500 AE Enschede, \\ The Netherlands
}

(First received 20 December 1991; accepted in revised form 26 May 1992)

\begin{abstract}
Gas solids mass transfer was studied for counter-current flow of gas and millimetre-sized solid particles over an inert packing at dilute phase or trickle flow conditions. Experimental data were obtained from the adsorption of water vapour on 640 and $2200 \mu \mathrm{m}$ diameter molecular sieve spheres at ambient conditions in a test column with a cross-sectional area of $0.06 \times 0.06 \mathrm{~m}^{2}$ and a packing height of 0.27 or $0.53 \mathrm{~m}$. The packing consisted of a bank of regularly stacked, $0.01 \mathrm{~m}$ diameter bars made of stainless steel. Assuming the effective area for mass transfer to be equal to the external surface area of the spheres, the experimental values of the average gas-solids mass transfer coefficient were determined to amount to approximately $40-80 \%$ of the values calculated from the well-known Ranz-Marshall correlation for a single sphere in an undisturbed gas flow. These experimental values were identified as conservative estimates of the actual average gas-solids mass transfer coefficient because the pore diffusion resistance could not be eliminated completely. A comparison between experimental data on hydrodynamics (gas-solids momentum transfer) and gas-solids mass transfer indicated, furthermore, that the influence of particle shielding with interfering concentration boundary layers of different particles was small for the millimetre-sized particles and the experimental conditions investigated. Gas-solids mass transfer as well as gas-solids momentum transfer were mainly determined by single-particle flow behaviour.
\end{abstract}

\section{INTRODUCTION}

In a gas solid trickle flow reactor (GSTFR), gas and solids are contacted counter-currently over a packed column under dilute phase or trickle flow conditions. The potential of this relatively new type of gas-solids contactor for gas treating, adsorption and heat recovery has been shown in several previous studies (Verver and van Swaaij, 1987; Kuczynski, 1986; Guigon et al., 1986). As reported in earlier publications (Kiel et al., 1990; Kiel, 1990), our research is focused on the application of a gas-solid trickle flow reactor as the absorber in a continuous dry regenerative process for the simultaneous removal of $\mathrm{SO}_{x}$ and $\mathrm{NO}_{x}$ from flue gases. A gas-solid trickle flow reactor is expected to be an efficient absorber because of favourable properties such as a low pressure drop, little axial mixing in both phases and high rates of gas-solids heat and mass transfer. Relatively large solid particles (millimetre-sized) are to be preferred because they allow a high superficial flue gas velocity (1-5 $\left.\mathrm{m} \mathrm{s}^{-1}\right)$, which limits the required cross-sectional area of the absorber. Hydrodynamic properties, particularly pressure drop and average solids hold-up, for trickle flow of relatively large particles over several specially designed, regularly stacked packings have been described by Kiel and van Swaaij (1989) and Kiel (1990). In this paper, the resuits of a subsequent study of gas-solids mass transfer are presented.

Gas-solids mass transfer for small particles (average particle diameter $70 \mu \mathrm{m}$ ) under trickle flow conditions was investigated by Roes and van Swaaij (1979b)

†Present address: Netherlands Energy Research Foundation ECN, P.O. Box 1, 1755 ZG Petten, The Netherlands. for a packed column of Pall rings, and by Verver and van Swaaij (1987) for a double-channel baffle column. In both studies, the experimentally obtained values of the mass transfer rate constant, $k_{\theta} a$, were at least a factor of 100 lower than the values calculated from experimental solids hold-up data and the well-known correlation of Ranz and Marshall (1952) for mass transfer between a single sphere and its surrounding gas phase. The low experimental $k_{g} a$ values were attributed to particle shielding phenomena due to the formation of less dilute suspensions or trickles, as they were called on the basis of visual observations of their appearance. Formation of trickles is likely to occur because it reduces the friction force experienced by the particles. The above-mentioned hydrodynamic study, and also the experimental data of Verver and van Swaaij (1986a), however, clearly indicate that the influence of particle shielding phenomena decreases considerably with increasing particle diameter. Therefore, a smaller difference between experimental and calculated $k_{\theta} a$ values may be expected for larger particles.

This is supported by a study of Verver and van Swaaij (1986b), in which gas-solids heat transfer was investigated under trickle flow conditions in a column (cross-sectional area $0.15 \times 0.15 \mathrm{~m}^{2}$ ) containing a regularly stacked packing of bars with a square crosssectional area of $0.02 \times 0.02 \mathrm{~m}^{2}$, while using $370 \mu \mathrm{m}$ sand particles for the solids phase. The obtained experimental values of the heat transfer rate constant, $\alpha a$, were only about a factor of three smaller than the ones calculated from the Ranz-Marshall correlation for heat transfer (Ranz and Marshall, 1952).

Kato et al. (1983) also report relatively high rates of gas-solids heat transfer for counter-current flow of 
wet activated alumina spheres (317-832 $\mu \mathrm{m}$ diameter) and hot air in a bed of open-end cylindrical sereen packings (equivalent diameter $3.61 \mathrm{~cm}$ ). The heat transfer coefficient $\alpha$ was determined from the inlet and outlet gas temperature, assuming (i) the evaporation rate of water from the spheres to be determined by gas-solids mass and heat transfer only (constant drying rate period), (ii) the solids temperature to be equal to the wet-bulb temperature of the inlet gas, and (iii) the effective area for heat transfer to be equal to the external surface area of the spheres. They found $\alpha$ to increase with increasing particle Reynolds number, and also with decreasing average solids hold-up, $\bar{\beta}$. For very low values of $\bar{\beta}$ ( $\leqslant 0.001)$, the $\alpha$ values approximately agreed with the values calculated from the Ranz-Marshall correlation (see also Fig. 7).

Probably, the actual mass transfer rates for counter-current flow of gas and millimetre-sized particles in a GSTFR can be estimated more accurately from these heat transfer data, while making use of the Chilton-Colburn analogy (Chilton and Colburn, 1934), than from an extrapolation of the mass transfer data for small particles. However, in case of a different packing configuration and different particle properties (density, diameter) this estimation may still be rather rough. Moreover, radiation and heat transfer between gas and solids via the packing may have influenced the gas-solids heat transfer measurements, and do not have a counterpart in case of mass transfer experiments. Therefore, the present study was carried out to determine the gas-solids mass transfer for the specific conditions of the gas-solid trickle flow absorber in the bench-scale plant which was built to investigate the overall performance of the flue gas treating process. Gas-solids mass transfer rate constants were evaluated from adsorption experiments, in which previously dried $4 \AA$ molecular sieve particles werc contacted in the absorber of the bench-seale plant at ambient temperature, with a nitrogen flow containing 0.6-1.5 vol\% water vapour.

\section{THEORY}

In a gas-solid trickle flow reactor, the interaction between the upwards flowing gas and the downwards flowing solid particles is very complex and difficult to describe. Some of the flow phenomena causing this complexity have been discussed previously (Kiel and van Swaaij, 1989), e.g. the turbulent flow pattern of the gas phase in the presence of large wakes beyond the packing elements and the previously mentioned formation of trickles. In a simple approach, however, the overall gas solids mass transfer can be described making the following assumptions for the gas and the dilute solids flow:

(a) The solid particles are spherical and flow downwards with the time-averaged solids velocity

$$
u_{s}=\bar{u}_{s}=\frac{S}{\bar{B} \rho_{s}}
$$

(b) The particles are considered to flow individually without any mutual interference of their concentration boundary layers.

(c) The gas flow is independent of the presence of solid particles.

(d) The upward gas velocity is constant and equal to

$$
u_{g}=\frac{G}{\varepsilon \rho_{g}} .
$$

With these assumptions, the total interfacial area is equal to the total external surface area of the solid particles and the gas-solids mass transfer coefficient, $k_{g}$, is constant throughout the column. $k_{g}$ can be calculated from the correlation of Ranz and Marshall (1952) for a single sphere in an undisturbed gas flow according to

$$
S h=\frac{k_{g} d_{s}}{D_{A}}=2.0+0.6 R e^{1 / 2} S c^{1 / 3}
$$

with the Reynolds number defined as

$$
R e=\frac{\rho_{g} d_{s}\left|u_{s}-u_{g}\right|}{\mu_{g}} .
$$

In fact, both the local gas and solids velocity and, therefore, the local slip velocity, $\left|u_{s}-u_{g}\right|$, will differ from the constant values defined above. In a hydrodynamic model presented earlier (Kiel and van Swaaij, 1989), the overall effect of these different local velocities and of particle shielding on the gas-solids momentum transfer is accounted for by defining an effective gas velocity according to

$$
u_{g \in f f}=\xi \frac{G}{\varepsilon \rho_{g}}
$$

in which $\xi$, the hydrodynamic effectiveness factor, is an empirical parameter. Values of $\xi$ were determined for various conditions by a comparison of experimental and calculated values (using the hydrodynamic model) of the average solids hold-up, $\bar{\beta}$, at relativcly high valucs of the gas mass flux, $G$. In the case of a packing type as applied in this study, and with glass beads for the solids phase, $\xi$ was found to be 1.2-1.5 for a particle diameter of $200-750 \mu \mathrm{m}$ and a solids mass flux of $1-2 \mathrm{~kg} \mathrm{~m}^{-2} \mathrm{~s}^{-1}$. Obviously, the actual momentum transfer was larger than the one calculated using the gas velocity, $u_{g}=G / \varepsilon p_{g}$. Based on these results, the average mass transfer coefficient, $k_{a}$, may be expected to be slightly higher than the one calculated according to the simple approach presented above [eqs (1)-(4)]. On the other hand, however, a possible mutual interference of the concentration boundary layers of different particles will lead to lower values of $k_{g}$.

In conclusion, it is unlikely that the simple model based on the Ranz-Marshall correlation will give an accurate description of gas-solids mass transfer in a gas-solid trickle flow reactor. However, a general mass transfer correlation more tailored to the special case of gas-solid trickle flow is not available yet. 
Furthermore, a comparison of the experimental mass transfer data with the values calculated from this simple model can be very fruitful, because it enables a discussion on the influence of phenomena like particle shielding and mutual interference of concentration boundary layers.

To determine the actual average gas-solids mass transfer coefficients from the adsorption experiments in the gas-solid trickle flow reactor (GSTFR), a simple one-dimensional two-phase model was used. The trickle-phase model, introduced by Verver and van Swaaij (1987) to account for the formation of trickles, was not applied because the influence of particle shielding phenomena was expected to be small for the millimetre-sized particles investigated. Radial effects such as segregation over the column diameter and solids-wall interactions are likely to be negligible due to the good radial (re-)distribution properties of the regularly stacked packing applied.

The amount of axial dispersion in the gas phase may be estimated from experimental data presented by Roes and van Swaaij (1979a) and Noordergraaf et al. (1980) for counter-current flow of air and $70 \mu \mathrm{m}$ fluid cracking catalyst particles in a packed column of $0.015 \mathrm{~m}$ Pall rings and in a baffle column, respectively. Based on their experimental results, it seems reasonable to assume that the height of a gas-phase mixing unit will approximately be equal to the height of 1 to 2 packing layers at the high superficial gas velocities applied $\left(\geqslant 0.35 \mathrm{~m} \mathrm{~s}^{-1}\right)$. This assumption results in a gas-phase Péclet number of $27-54$ for the $27 \mathrm{~cm}$ column and 53-106 for the $53 \mathrm{~cm}$ column applied in the present study, i.e. a distinct plug flow behaviour of the gas phase. Axial dispersion in the solids phase hardly affects the reactor performance if the change in water vapour loading of the particles during their fall through the GSTFR remains relatively small.

In the case of plug flow for both phases, the water vapour concentration in the gas phase is given by the following differential equation:

$$
U_{g} \frac{\mathrm{d} C}{\mathrm{~d} z}+k_{g} a\left(C-C_{i}\right)=0 .
$$

Its boundary condition is: $C=C_{\text {int }}$ at $z=0$. The axial coordinate $z$ is taken to be positive in upward direction. $k_{g} a$ is the average rate constant for the gas-solids mass transfer and $C_{i}$ the water vapour concentration at the gas-solids interface. The specific interfacial area, $a$, is supposed to be equal to the specific external surface area of the particles, which is calculated from the experimentally determined average solids holdup, $\bar{\beta}$, according to

$$
a=\frac{6 \bar{\beta}}{d_{s}} .
$$

Therefore, effects of particle shielding phenomena on gas-solids mass transfer will appear in the values of the average mass transfer coefficient, $k_{\theta}$. Using eq. (6) and calculating $a$ according to eq. (7), $k_{g}$ can be evaluated from the experimental values of the inlet and outlet concentrations of water vapour in the gas phase provided that the interface concentration $C_{i}$ is known as a function of the column height.

For the case of $\mathrm{H}_{2} \mathrm{O}$ loadings of the porous molecular sieve particles close to zero, the equilibrium water vapour concentration will be negligible compared to inlet vapour concentrations of $C_{\text {in }}=0.6-1.5 \mathrm{vol} \%$ and outlet vapour concentrations of $C_{\text {out }} \geqslant 0.2 C_{i n}$, as applied in this study (see the adsorption isotherms of the applied molecular sieves presented in Fig. 1). Therefore, initially all the water vapour transported from the bulk of the gas phase to the particles will be readily adsorbed close to the particle outer surface. The adsorption rate will be completely determined by gas-solids mass transfer and the interface concentration $C_{i}$ may be taken equal to zero. Solution of eq. (6) then yields

$$
k_{g}=-\frac{U_{a}}{a L} \ln \left(C_{o u t} / C_{t n}\right) .
$$

Due to a limited pore diffusion rate, however, the amount of water vapour adsorbed will not be homogeneously distributed over the relatively large-sized particles. A radial concentration gradient of adsorbed $\mathrm{H}_{2} \mathrm{O}$ will develop, with the concentration increasing at increasing radial distance from the particle centre. This will cause the interface concentration $C_{i}$ to be higher than that calculated from the average $\mathrm{H}_{2} \mathrm{O}$ loading according to the adsorption isotherm. As a result, the value of $C_{i}$ may already start becoming important at low average $\mathrm{H}_{2} \mathrm{O}$ loadings, for which the average equilibrium concentration is. still negligible compared to the concentration in the bulk of the gas phase. Basically, it is possible to determine the interface concentration $C_{i}$ as a function of the column height if the diffusion coefficients for gas phase diffusion and for surface diffusion inside the molecular sieve particles are known. This is not the case for the molecular sieve particles applied, however, and determination of these diffusion coefficients was outside the scope of this study.

If the actual value of $C_{i}$ is not negligibly small under the experimental conditions chosen, then calculation of $k_{g}$ from the experimental inlet and outlet vapour concentrations according to $\mathrm{eq}$. (8) will result in a conservative estimate because of an overestimation of the driving force, $C-C_{i}$. Equation (8) then yields an apparent gas-solids mass transfer coefficient, $k_{g}^{*}$, with $k_{g}^{*} \leqslant k_{g}$. The lower the initial $\mathrm{H}_{2} \mathrm{O}$ loading and the increase of the loading in the column, the closer will $k_{g}^{*}$ approximate $k_{g}$.

\section{EXPERIMENTAL}

\subsection{Adsorbent properties}

Two different size fractions of $4 \AA$ molecular sieve spheres manufactured by Grace (type MS511 and MS514) were used as the water-adsorbing solids phase. The particle size distribution (for the small-size fraction only), the average particle diameter and the average particle density (on a dry basis) of both size fractions are presented in Table 1. Typical adsorption isotherms for water are given in Fig. 1. Before the 
Table 1. Properties of the two molecular sieve size fractions applied

\begin{tabular}{lr}
\hline Pore diameter $(\dot{A})$ & 4 \\
Internal surface area $\left(\mathrm{m}^{2} \mathrm{~g}^{-1}\right)$ & \pm 800 \\
\hline
\end{tabular}

$640 \mu \mathrm{m}$ size-fraction (Grace MS511)

Particle size distribution (from sieve analysis)

\begin{tabular}{ccc}
$d\left(10^{-6} \mathrm{~m}\right)$ & $w t \%$ & $\begin{array}{c}\text { Cumulative } \\
\text { wt \% }\end{array}$ \\
\hline$<420$ & 0.2 & 0.2 \\
$420-500$ & 2.7 & 2.9 \\
$500-600$ & 37.1 & 40.0 \\
$600-707$ & 26.2 & 66.2 \\
$707-850$ & 33.0 & 99.2 \\
$850-900$ & 0.7 & 99.9 \\
$>900$ & 0.1 & 100.0
\end{tabular}

Average particle diameter $\left(10^{-6} \mathrm{~m}\right)$

Average apparent density $\left(\mathrm{kg} \mathrm{m}^{-3}\right)$

Terminal velocity in $\mathrm{N}_{2}$ at $25^{\circ} \mathrm{C}$,

$1 \mathrm{~atm}\left(\mathrm{~ms} \mathrm{~s}^{-1}\right)$

640

1533

3.4

$2200 \mu \mathrm{m}$ size-fraction (Grace MS514)

Particle diameter range $\left(10^{-6} \mathrm{~m}\right)$

Average particle diameter $\left(10^{-6} \mathrm{~m}\right)$

Average apparent density $\left(\mathrm{kg} \mathrm{m}^{-3}\right)$

Terminal velocity in $\mathrm{N}_{2}$ at $25^{\circ} \mathrm{C}$,

$1 \mathrm{~atm}\left(\mathrm{~ms}^{-1}\right)$

molecular sieves were applied in the adsorption experiments, they were first dried for approximately $3 \mathrm{~h}$ in a separate fluidised bed operated with dry air at $300-350^{\circ} \mathrm{C}$. Then the heating as well as the air supply were switched off, and the molecular sieves were cooled to $100-150^{\circ} \mathrm{C}$. Subsequently, they were collected in an air-tight vessel and allowed to cool further to ambient temperature. From this air-tight vessel, they were finally fed into the upper storage vessel of the experimental set-up (see Fig. 2). After each pass of the molecular sieves through the packed column during an adsorption experiment, this drying procedure was repeated to ensure the same low level of initial $\mathrm{H}_{2} \mathrm{O}$ loading in all experiments.

\subsection{Experimental set-up}

The experimental set-up is shown in Fig. 2. The GSTF section (5) contained a packing configuration consisting of regularly stacked, $0.01 \mathrm{~m}$ diameter cylin-

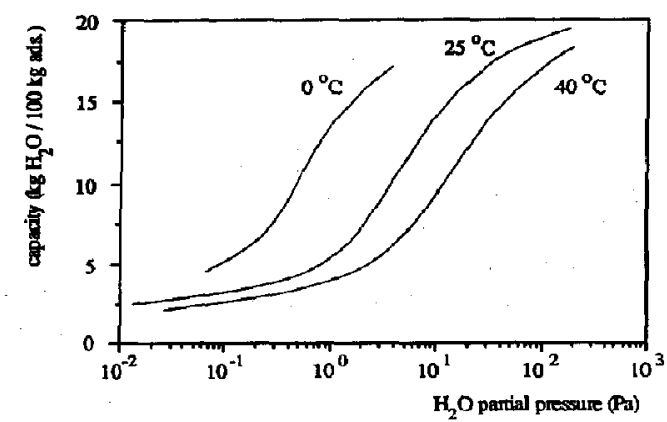

Fig. 1. Typical adsorption isotherms for water on Grace MS511 and Grace MS514 molecular sieves.

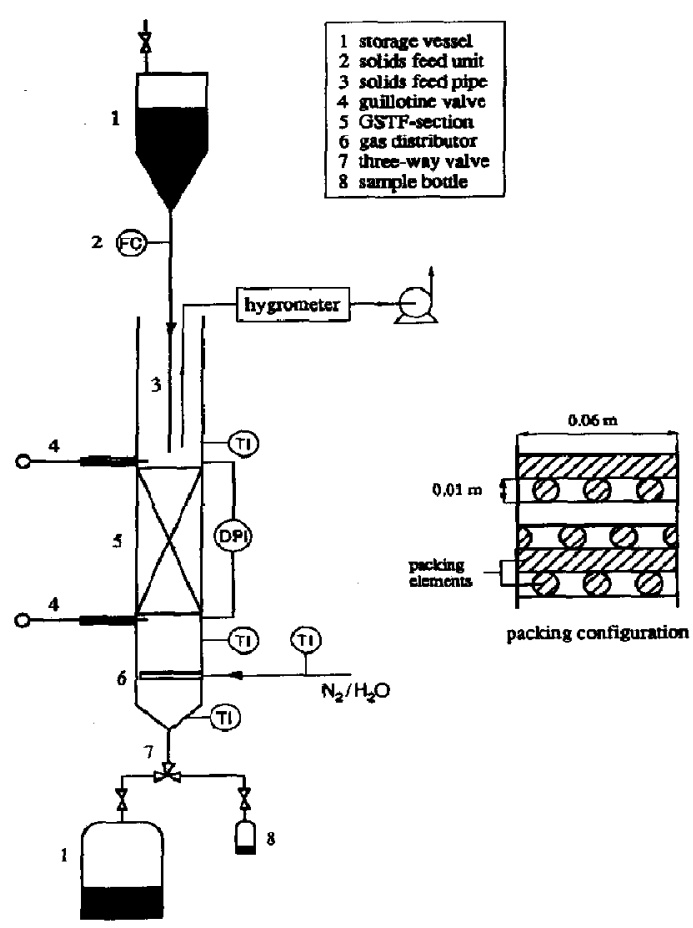

Fig. 2. Experimental set-up. Packed column: cross-sectional area $0.06 \times 0.06 \mathrm{~m}^{2}$, packing length 0.53 or $0.27 \mathrm{~m}$.

drical bars made of stainless steel. The applied total packing height was 0.53 or $0.27 \mathrm{~m}$.

The solids were supplied batchwise to allow intermediate regeneration in a separate fluidised bed as described in Section 3.1. A specially designed solids 
feed unit (2), similar to the one described by Horsley and Rothwell (1972), provided a constant solids flow rate. The solids feed pipe (3) ended just above the packing to minimise the initial water vapour loading of the sorbent particles. Despite the presence of only one feed point for the solids, a good radial distribution of the solids phase was achieved within approximately five packing layers due to the good radial distribution properties of the packing itself. The solids mass flow rate was measured by collecting the solids flow below the GSTF section in a sample bottle (8) during a certain time interval, and subsequently weighing the obtained sample. The average solids hold-up in the packed section could be determined by simultaneously closing two guillotine valves (4), one just above and the other just below the packing.

The gas phase consisted of $0.6-1.5 \mathrm{vol} \%$ water vapour in nitrogen. Water was supplied by a calibrated tubing pump to an evaporation vessel placed on a stove. The resulting water vapour was subsequently mixed with technical grade nitrogen (UCAR) by means of a sprayer. A gas distributor (6), consisting of two horizontal pipes with a closed end and a regular pattern of $1 \mathrm{~mm}$ holes on the top side, was used to achieve a good initial gas distribution in the column.

The outlet water vapour concentration was determined by withdrawing a small gas sample (about $50 \mathrm{ml} \mathrm{min}$ ) from just above the packing and leading it to a hygrometer (Testo 6400). This instrument measures the relative humidity and the temperature of the sample simultaneously. The relative humidity (RH) is measured with an accuracy of \pm 0.02 for $R H$ $=0.05-0.98$ and the accuracy of the temperature measurement is $\pm 0.15^{\circ} \mathrm{C}$. Experiments with $R H$ values outside the range of $0.05-0.95$ were not taken into account. The inlet water vapour concentration was always determined by measuring the outlet concentration at zero solids flow rate.

\section{RESULTS AND DISCUSSION}

\subsection{Hydrodynamics}

In Fig. 3, experimental values of the average solids hold-up, $\bar{\beta}$, are presented for both size fractions and different solids mass fluxes. Also indicated is the gas mass flux, for which the gas velocity in the minimal open cross-sectional area of the packing (which is $50 \%$ of the total cross-sectional area of the column) is equal to the terminal or free-falling velocity of the solid particles ( $\left.G=\rho_{g} u_{t} / 2\right)$. It appears that the loading regime, characterised by a sharp increase of the average solids hold-up, $\bar{\beta}$, at increasing gas mass flux $G$, starts at relatively low $G$ values (approximately at $\left.G=\rho_{g} u_{t} / 4\right)$. This is probably caused by a combination of limited particle shielding and relatively high solids hold-up values. Verver and van Swaaij (1986a) obtained $\bar{\beta}$ vs $G$ curves for $70 \mu \mathrm{m}$ diameter fluid cracking catalyst particles flowing over a regularly stacked packing of bars with a $1.4 \times 1.4 \mathrm{~cm}^{2}$ crosssectional area. For solids mass fluxes ranging from 0.21 to $0.75 \mathrm{~kg} \mathrm{~m}^{-2} \mathrm{~s}^{-1}$, they found the loading
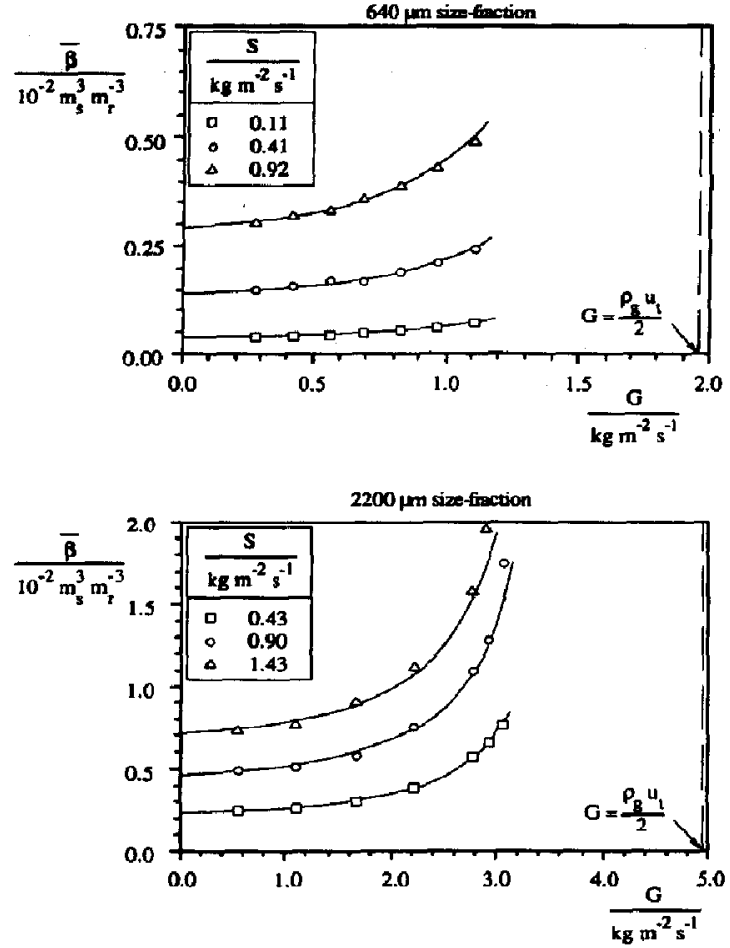

Fig. 3. Average solids hold-up vs gas mass flux at ambient conditions for both molecular sieve size fractions. The symbols represent experimental values, while the lines are calculated from the hydrodynamic model presented by Kiel and van Swaaij (1989). Best-fit values of the two empirical parameters are given in Table 2. Also indicated is the gas mass flux, for which the gas velocity in the minimum open crosssectional area of the packing (which is $50 \%$ of the total crosssectional area of the column) is equal to the terminal velocity of the solid particles $\left(G=\rho_{g} u_{t} / 2\right)$.

regime to start at a much higher $G$ value of about $1.5 \rho_{g} u_{t}$. Apparently, the influence of particle shielding and agglomeration is considerably larger for these small particles than for the millimetre-sized particles investigated in the present study. Figure 3 shows, in addition, that the start of the loading regime shifts slightly to lower $G$ values at increasing $S$. This may be caused by the corresponding increase of $\bar{\beta}$.

The experimentally obtained $\bar{\beta}$-values were used to obtain best-fit values for the two empirical parameters of the one-dimensional hydrodynamic model, viz. the previously mentioned hydrodynamic effectiveness factor, $\xi$, and the initial solids velocity, $u_{s 0}$. The latter represents the solids velocity just after the collision of a solid particle with a packing element and includes the influence of particle-particle interaction during this collision. The best-fit values of $u_{x 0}$ and $\xi$ can be obtained independently from a comparison of the measured and the calculated values of the average solids hold-up, $\beta$, at low and high gas mass fluxes, respectively (see Kiel and van Swaaij, 1989).

A comparison of the best-fit values given in Table 2 for the two molecular sieve size fractions and different 
Table 2. Best-fit values of the two empirical parameters of the hydrodynamic model for the two molecular sieve size fractions at different solids mass fluxes ( $u_{s 0}$ is positive in downward direction)

\begin{tabular}{lccc}
\hline & $\begin{array}{c}S \\
\left(\mathrm{~kg} \mathrm{~m}^{-2} \mathrm{~s}^{-1}\right)\end{array}$ & $\begin{array}{c}u_{s 0} \\
\left(\mathrm{~m} \mathrm{~s}^{-1}\right)\end{array}$ & $\xi$ [see eq. (5)] \\
\hline $640 \mu$ m diameter fraction & 0.11 & -0.08 & 1.6 \\
& 0.41 & -0.06 & 1.6 \\
$2200 \mu$ m diameter fraction & 0.92 & -0.03 & 1.6 \\
& 0.43 & -0.20 & 1.8 \\
& 0.90 & -0.17 & 1.8 \\
& 1.43 & -0.15 & 1.8 \\
\hline
\end{tabular}

solids mass fluxes shows similar trends as reported by Kiel and van Swaaij (1989). First, the initial solids velocity, $u_{s 0}$, increases at increasing $S$, which is attributed to an increasing particle-particle interaction when the particles are bouncing on the packing elements. Secondly, the $2200 \mu \mathrm{m}$ size fraction yields a lower value for $u_{s 0}$ and a higher value for $\xi$ than the $640 \mu \mathrm{m}$ size fraction at the same $S$. This is related to the lower number of particles flowing through the column for the large-size fraction, which results in less particle-particle interaction during the bouncing of particles on packing elements and less particle shielding during their fall from one packing element to another.

In summary, these hydrodynamic measurements are clearly in agreement with the conclusions drawn above from the literature. The millimetre-sized molecular sieve particles show only a limited degree of particle shielding, resulting in relatively large negative values of the initial solids velocity, $u_{s 0}$ (the particles bouncing) and high values of the hydrodynamic effectiveness factor, $\xi$. The values of $\xi=1.6$ for the $640 \mu \mathrm{m}$ size fraction and $\xi=1.8$ for the $2200 \mu \mathrm{m}$ size fraction indicate that the average mass transfer coefficient may even be higher than that calculated according to the simple approach represented by eqs (1)-(4).

\subsection{Gas-solids mass transfer}

The first series of adsorption experiments was carried out with a packing length of $0.53 \mathrm{~m}$ using the $640 \mu \mathrm{m}$ molecular sieve size fraction for the solids phase. Experimental ranges for the gas and solids mass flux were set by three conditions, viz. (i) a significant decrease of the water vapour concentration in the gas phase $\left(C_{\text {out }} / C_{\text {in }} \leqslant 0.9\right)$, (ii) at least $5 \%$ relative humidity at the gas outlet, and (iii) stable countercurrent operation (no loading, see Fig. 3). By applying eq. (8) and, thus, neglecting the possible influence of pore diffusion, the apparent gas-solids mass transfer coefficient, $k_{\theta}^{*}$, was determined from the measured inlet. and outlet water vapour concentrations. From experiments with different inlet concentrations, viz. $C_{i n}=0.6,1.0$ and $1.5 \mathrm{vol} \%$, it was found that the $k_{g}^{*}$ value increased with a decreasing $C_{i n}$. This indicated that it was not justified to neglect the pore diffusion resistance and to take the interface concentration $C_{i}$ equal to zero.
To illustrate the influence of the pore diffusion resistance, the experimental $k_{g}^{*}$ values are shown in Fig. 4 as a function of the amount of water adsorbed on the molecular sieve particles, or the increase of the $\mathrm{H}_{2} \mathrm{O}$ loading, $\zeta_{\text {out }}-\zeta_{\text {in }}$, during their fall through the packed column. $\zeta_{\text {out }}-\zeta_{\text {in }}$ was calculated according to

$$
\zeta_{\text {nut }}-\zeta_{\text {in }}=\frac{M_{\mathrm{H}_{2} \mathrm{O}} G}{\rho_{g} S}\left(C_{\text {in }}-C_{\text {out }}\right)
$$

To eliminate the gas-solids mass transfer contribution in the entry section, the inlet water vapour concentration $C_{\text {in }}$ was corrected for adsorption in that section. Between the gas distributor and the packing (column length $0.12 \mathrm{~m}$ ), the following conditions were assumed to be valid:

- Gas-solids mass transfer is the rate-determining step.

- Axial dispersion is negligible in both phases.

- The effective interfacial area for mass transfer is equal to the external surface area of the particles.

- The Ranz-Marshall correlation applies for the mass transfer coefficient, $\boldsymbol{k}_{\boldsymbol{s}}$.

- The gas velocity is equal to the superficial gas velocity in the column.

- The solids velocity is equal to the time-averaged velocity, $\bar{u}_{s}$, as calculated from the hydrodynamic model with $\xi=1$ and $u_{s 0}$ as presented in Table 2 .

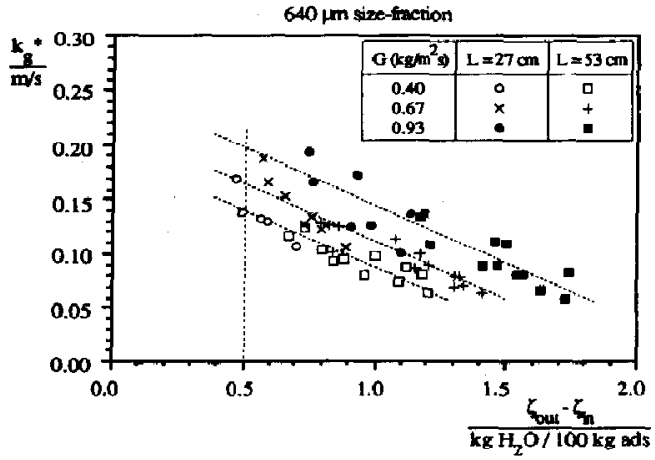

Fig. 4. Values of the apparent gas-solids mass transfer coefficient, $k_{0}^{*}$, as calculated from the experimental values of $C_{t n} / C_{\text {ouf }}$ by eq. (8), vs the increase of the $\mathrm{H}_{2} \mathrm{O}$ loading $\zeta_{\text {our }}-\zeta_{\text {in }}$ for the $640 \mu \mathrm{m}$ size fraction at different gas mass fluxes, $G$. 
According to these assumptions, about $15 \%$ of the total decrease in water vapour concentration took place in this entry section in case of the $0.53 \mathrm{~m}$ column. This percentage will be even lower if, to a certain extent, pore diffusion is also involved in the transfer process.

In Fig. 4, the increase of $k_{g}^{*}$ with a decreasing $\zeta_{\text {out }}-\zeta_{\text {in }}$ clearly reflects the influence of pore diffusion. But the increase of $k_{\theta}^{*}$ with increasing gas mass flux, $G$, at the same $\zeta_{\text {out }}-\zeta_{\text {in }}$ indicates a distinct influence of gas-solids mass transfer on the adsorption rate as well. The experimental results of Fig. 4 are not affected by the value of the solids mass flux, $S$. However, $S$ could be varied only over a limited range, viz. from 0.09 to $0.20 \mathrm{~kg} \mathrm{~m}^{-2} \mathrm{~s}^{-1}$.

To achieve $\mathrm{H}_{2} \mathrm{O}$ loadings which are low enough for the gas-solids mass transfer to become rate-determining, some experiments were conducted with a packing height of $0.27 \mathrm{~m}$ instead of $0.53 \mathrm{~m}$, with the solids mass flux, $S$, varied between 0.19 and $0.38 \mathrm{~kg} \mathrm{~m}^{-2} \mathrm{~s}^{-1}$. As expected, these experiments yielded a further increase of $k_{g}^{*}$ at lower values of $\zeta_{\text {out }}-\zeta_{\text {in }}$, but it seems that the maximum values of $k_{g}^{*}\left(=k_{g}\right)$ were not yet reached. Apparently, the influence of pore diffusion was still considerable. Just as for the $0.53 \mathrm{~m}$ column, variation of $S$ within the given limited range yielded the same $k_{g}^{*}$ vs $\zeta_{\text {out }}-\zeta_{\text {in }}$ curve. Unfortunately, the actual average gas-solids mass transfer coefficient, $k_{g}$, cannot be deduced from the experimental data presented in Fig. 4.

This problem is illustrated in Fig. 5, where some speculative extrapolations of the observed $k_{g}^{*}$ vs $\zeta_{\text {out }}-\zeta_{\text {in }}$ curves are sketched for the loading regime $\zeta_{\text {our }}-\zeta_{\text {in }}<0.5 \mathrm{wt} \%$, which can be expected if the intrinsic adsorption is instantaneous and if $\zeta_{\text {in }}=0$. At very low $\mathrm{H}_{2} \mathrm{O}$ loadings, the interface concentration $C_{i}$ is equal to zero and the adsorption rate is completely determined by gas-solids mass transfer $\left(k_{g}^{*}=k_{g}\right)$. If the $\mathrm{H}_{2} \mathrm{O}$ loading increases, pore diffusion starts to become important. As a consequence, $C_{i}>0$ and $k_{g}^{*}<k_{g}$. The shape of the curve for higher $\mathrm{H}_{2} \mathrm{O}$

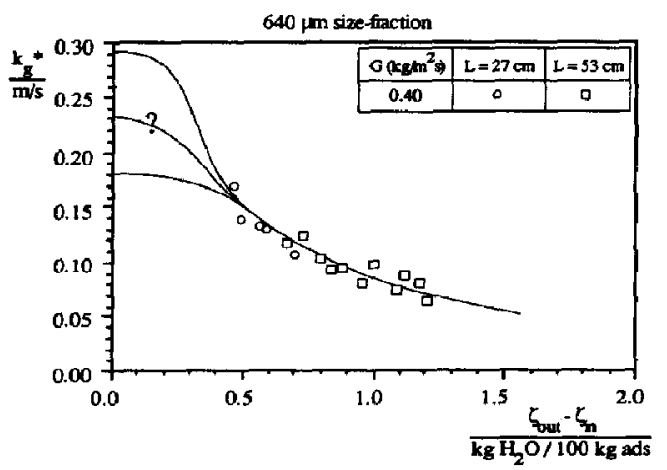

Fig. 5. Illustration of the problem of how to derive the value

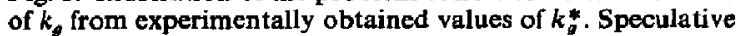
extrapolations of the apparent gas solids mass transfer coefficient, $k_{g}^{*}$, to $\zeta_{\text {out }}-\zeta_{\text {in }}=0$ are shown. The experimental data are identical to the ones presented in Fig. 4 for the $640 \mu \mathrm{m}$ size fraction at $G=0.40 \mathrm{~kg} \mathrm{~m}^{-2} \mathrm{~s}^{-1}$. loadings, $\zeta$, will depend on the way in which the pore diffusion coefficients, for gas phase diffusion of water vapour and for surface diffusion of absorbed water, are related to $\zeta$. Finally, $k_{g}^{*}=0$ will be reached at a $\mathrm{H}_{2} \mathrm{O}$ loading equal to the saturation capacity of the molecular sieve particles for the applied temperature and inlet water vapour concentration. Since the diffusion coefficients are unknown for the molecular sieve particles applied, and the initial $\mathrm{H}_{2} \mathrm{O}$ loading, $\zeta_{\text {in }}$, may deviate from zero, extrapolation of $k_{g}^{*}$ to determine the actual average mass transfer coefficient, $k_{g}$, at $\zeta=0$ is impossible.

Nevertheless, the experiments do provide conservative estimates for $k_{g}$. The straight lines in Fig. 4 were calculated from the experimental data by linear regression. For the three mass fluxes investigated, these straight lines appear to have the same slope. Conservative estimates for $k_{g}$ are taken to be equal to the values of $k_{g}^{*}$ at $\zeta_{\text {out }}-\zeta_{\text {in }}=0.5 \mathrm{wt} \%$ according to these lines.

Experiments with the $2200 \mu \mathrm{m}$ molecular sieve size fraction were carried out only for a packed column length of $0.53 \mathrm{~m}$. The solids mass flux, $S$, was varied between 0.20 and $0.74 \mathrm{~kg} \mathrm{~m}^{-2} \mathrm{~s}^{-1}$ for gas mass fluxes $G=0.40-0.93 \mathrm{~kg} \mathrm{~m}^{-2} \mathrm{~s}^{-1}$, and between 1.15 and $1.84 \mathrm{~kg} \mathrm{~m}^{-2} \mathrm{~s}^{-1}$ for $G=1.11-2.78 \mathrm{~kg} \mathrm{~m}^{-2} \mathrm{~s}^{-1}$. In Fig. 6 , the experimental $k_{g}^{*}$ values are given as a function of $\zeta_{\text {out }}-\zeta_{\text {in }}$ for different gas mass fluxes, $G$. Both $k_{g}^{*}$ and $\zeta_{\text {out }}-\zeta_{\text {in }}$ were corrected for the adsorption in the entry section between the gas distributor and the packing according to the assumptions described earlier for the $640 \mu \mathrm{m}$ size fraction. It appears that $k_{s}^{*}$ is nearly constant $\left(0.05-0.07 \mathrm{~m} \mathrm{~s}^{-1}\right)$ for all values of $\zeta_{\text {out }}-\zeta_{\text {in }}$. The $\mathrm{H}_{2} \mathrm{O}$ loading itself, however, increases with increasing gas mass flux, $G$, and, at a fixed value of $G$, with an increase of the inlet water vapour concentration $\left(C_{i n}=0.6,1.0\right.$ and $\left.1.5 \mathrm{vol} \%\right)$. Within the rather narrow experimental ranges, no distinct influence of the solids mass flux on $k_{g}^{*}$ or $\zeta_{\text {out }}-\zeta_{\text {in }}$ was observed. Most likely, the influence of pore diffusion was also considerable for this $2200 \mu \mathrm{m}$ size fraction. The presented $k_{g}^{*}$ values are then merely conservative

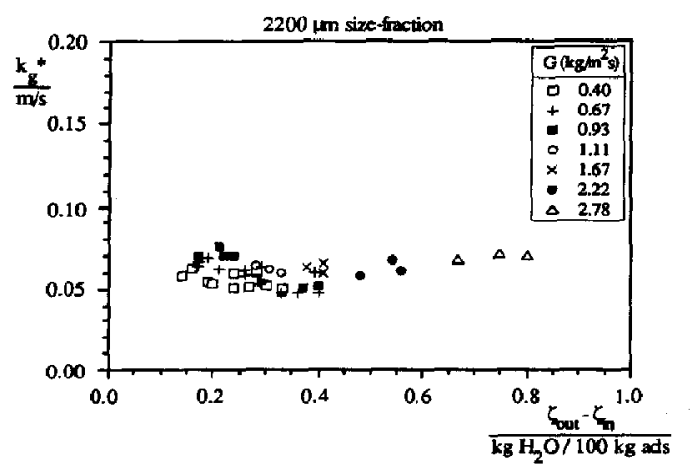

Fig. 6. Values of $k_{g}^{*}$, as calculated from the experimental values of $C_{I n} / C_{\text {out }}$ by eq. (8), vs the increase of the $\mathrm{H}_{2} \mathrm{O}$ loading, $\zeta_{\text {ow }}-\zeta_{\text {tn }}$, for the $2200 \mu \mathrm{m}$ size fraction at different gas mass fluxes, $G$. 
estimates of the actual average mass transfer coefficients, $k_{g}$.

Figure 7 shows a comparison between the Sherwood numbers based on the experimentally determined, conservative estimates of $k_{g}$ and Sherwood numbers calculated from the Ranz-Marshall correlation according to the rough approach presented in Section 2 [eqs (1)-(4)]. It appears that the conservative estimates amount to $40-80 \%$ of the theoretical $S h$ values.

As discussed in Section 4.1, the hydrodynamic measurements indicate that $k_{g}$ values should have been measured, which are somewhat higher than the ones calculated from eqs (1)-(4) if the adsorption rate was completely determined by gas-solids mass transfer, without any mutual interference of the concentration boundary layers of different particles. Unfortunately, it remains unclear which part of the difference between the expected and the actually measured values of $k_{g}$ is due to the pore diffusion resistance and which part to particle shielding, causing mutual interference of concentration boundary layers. However, from the results of the hydrodynamic measurements it can be concluded that the influence of particle shielding with interfering concentration boundary layers of different particles on gas-solid mass transfer is very limited for the millimetre-sized particles and the experimental conditions investigated.

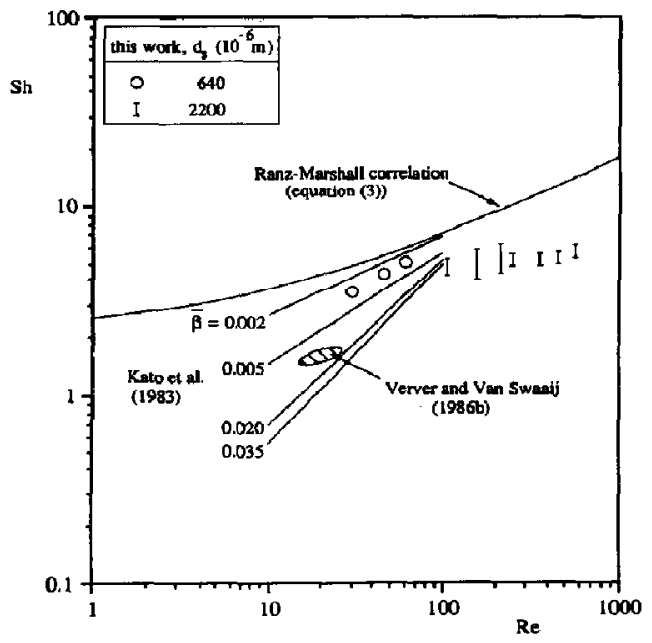

Fig. 7. Particle Sherwood number, $S h$, vs particle Reynolds number, $R e$. The open symbols represent values obtained from the experimental values of $k_{\theta}^{*}$ at $\zeta_{\text {our }}-\zeta_{\text {in }}=0.5$ for the $640 \mu \mathrm{m}$ molecular sieve size fraction. For the $2200 \mu \mathrm{m}$ size fraction. $S h$ ranges are indicated hased on the experimental ranges of $k_{g}^{*}$. Also shown are (i) the theoretical curve derived by using the Ranz-Marshall correlation according to the rough approach presented in Section 2 and (ii) the experimental data on gas-solids heat transfer reported by Verver and van Swaaij (1986b) and Kato et al. (1983) taking the Nusselt number, $N u$, equal to the Sherwood number, $S h$, and the interfacial area equal to the solids external surface area. From their experimental results, Kato et al. derived the following correlation: $N u=2.38 \times 10^{-3} R e^{n}[(1-\bar{\beta}) / \bar{\beta}]^{0.97}$, $n=2.48[(1-\bar{\beta}) / \bar{\beta}]^{-0.28}$.

\section{CONCIIISIONS}

The expected high rates of gas-solids mass transfer for counter-current flow of gas and millimetre-sized solid particles have been confirmed by the experimental results. Values of the average gas-solids mass transfer coefficient, $k_{g}$, were calculated from the decrease of the water vapour concentration over the height of the gas-solid trickle flow reactor by using a simple plug flow model. They amount to $40-80 \%$ of the theoretical values obtained by applying the wellknown Ranz-Marshall correlation for a single sphere in an undisturbed gas flow. In the plug flow model, it is assumed that (i) gas-solids mass transfer is the only resistance for the adsorption and (ii) the effective area for mass transfer is equal to the external surface area of the spheres. Unfortunately, it appeared to be impossible to choose the experimental conditions in a way that justified the first assumption. The pore diffusion resistance could not be eliminated completely. Consequently, the mass transfer coefficients presented are conservative estimates.

Despite the remaining influence of the pore diffusion resistance, however, it can be concluded from the experimental data on gas-solids mass transfer in combination with the experimental data on hydrodynamics (gas-solids momentum transfer) that the influence of particle shielding with interfering concentration boundary layers of different particles was small for the millimetre-sized particles and the experimental conditions investigated. Gas-solids mass transfer as well as gas-solids momentum transfer were mainly determined by single-particle flow behaviour.

\section{NOTATION}

$a$

$c$

$d_{\mathrm{s}}$

$D_{A}$

$D_{1}$

$G$

$k_{g}$

$k_{\boldsymbol{a}}^{*}$

$L$

$M$

$n$

$S$

$u_{g}$

$u_{\text {geff }}$

$u_{s}$

$\vec{u}_{s}$

$u_{t}$

$U_{g}$

$z$

\section{Greek symbols}

$\alpha$ specific interfacial area, $\mathrm{m}^{2} \mathrm{~m}_{\mathrm{reactor}}^{-3}$ gas-phase concentration, $\mathrm{mol} \mathrm{m}^{-3}$ average particle diameter, $\mathbf{m}$ molecular diffusion coefficient, $\mathrm{m}^{2} \mathrm{~s}^{-1}$ coefficient of axial dispersion, $\mathrm{m}^{2} \mathrm{~s}^{-1}$ gas mass flux, $\mathrm{kg} \mathrm{m}^{-2} \mathrm{~s}^{-1}$

(average) gas-solids mass transfer coefficient, $\mathrm{m} \mathrm{s}^{-1}$

apparent gas-solids mass transfer coefficient, $\mathrm{m} \mathrm{s}^{-1}$

packing length, $m$ molar mass, $\mathrm{kg} \mathrm{mol}^{-1}$

power of Re as applied by Kato et al. (1983) solids mass flux, $\mathrm{kg} \mathrm{m}^{-2} \mathrm{~s}^{-1}$

local gas velocity, $\mathrm{m} \mathrm{s}^{-1}$

effective gas velocity, $\mathrm{m} \mathrm{s}^{-1}$

local solids velocity, $\mathrm{m} \mathrm{s}^{-1}$

time-averaged solids velocity, $\mathrm{m} \mathrm{s}^{-1}$

terminal velocity, $\mathrm{ms}^{-1}$

superficial gas velocity, $\mathrm{m} \mathrm{s}^{-1}$

axial coordinate, $m$

\footnotetext{
average gas-solids heat transfer coefficient, $\mathbf{W} \mathbf{m}^{-2} \mathbf{K}^{-1}$ average solids hold-up, $\mathrm{m}^{3} \mathrm{~m}_{\text {reactor }}^{-3}$
} 
$\varepsilon \quad$ average packing porosity

$\zeta \quad \mathrm{H}_{2} \mathrm{O}$ loading, $\mathrm{kg} \mathrm{H} \mathrm{H}_{2} \mathrm{O} / 100 \mathrm{~kg}$ ads

$\lambda$ thermal conductivity, $\mathrm{W} \mathrm{m}^{-1} \mathrm{~K}^{-1}$

$\mu \quad$ dynamic viscosity, $\mathrm{kg} \mathrm{m}^{-1} \mathrm{~s}^{-1}$

$\xi$ hydrodynamic effectiveness factor [see

eq. (5)]

p density, $\mathrm{kg} \mathrm{m}^{-3}$

\section{Subscripts}

0 initial conditions

$g \quad$ gas phase conditions

$i$ conditions at the gas-solids interface

in inlet conditions

out outlet conditions

$s \quad$ solids phase conditions

\section{Dimensionless groups \\ $N u \quad$ particle Nusselt number $\left(=\alpha d_{s} / \lambda_{g}\right)$ \\ $\mathrm{Pe}_{\theta}$ gas-phase Péclet number $\left(=G L / \varepsilon \rho_{q} D_{1 \theta}\right)$ \\ $\operatorname{Re} \quad$ particle Reynolds number $\left(=\rho_{\theta} d_{s}\left|u_{s}-u_{g}\right| / \mu_{\theta}\right)$ \\ Sc Schmidt number $\left(=\mu_{g} / \rho_{g} D_{A}\right)$ \\ Sh particle Sherwood number $\left(=k_{q} d_{s} / D_{A}\right)$}

\section{REFERENCES}

Chilton, T, H. and Colburn, A. P., 1934, Mass transfer (absorption) coefficients. Ind. Engng Chem. 26, 1183-1187.

Guigon, P., Large, J. F. and Molodtsof, Y., 1986, Hydrodynamics of raining packed bed heat exchangers, in Encyclopaedia of Fluid Mechanics (Edited by N. P. Cheremisinoff), Vol. 4, Chap. 39. Gulf, Houston.

Horsley, D. M. C. and Rothwell, E., 1972, A laboratory scale feeder for non-cohesive powders. Powder Technol. 6, 117-120.
Kato, K, Onozawa, I. and Noguchi, Y., 1983, Gas-particle transfer in a dispersed bed. J. chem. Engng Japan 16, 178-182.

Kiel, J. H. A., 1990, Removal of sulphur oxides and nitrogen oxides from flue gas in a gas-solid trickle flow reactor. Ph.D. thesis, University of Twente, Enschede.

Kiel, J. H. A. and van Swaaij, W. P. M., 1989, A theoretical model for the hydrodynamics of gas-solid trickle flow over regularly stacked packings. A.I.Ch.E. Symp. Ser. 85(270), 11-21.

Kiel, J. H. A., Prins, W. and van Swaaij, W. P. M., 1990, Flue gas desulphurization in a gas-solid trickle flow reactor with a regenerable sorbent, in Process Technology Proceedings Vol. 8: Gas Separation Technology (Edited by E. F. Vansant and R. Dewolfs), pp. 539-548. Elsevier, Amsterdam.

Kuczynski, M., 1986, The synthesis of methanol in a gas-solid-solid trickle flow reactor. Ph.D. thesis, University of Twente, Enschede.

Noordergraaf, I. W., Roes, A. W. M. and van Swaaij, W. P. M., 1980, Proceedings 3rd International Conference on Fluidization, New Hampshire.

Ranz, W. E. and Marshall, W. R., 1952, Evaporation from drops. Chem. Engng Prog. 48(3), 141-146 (Part I); 48(4), 173-180 (Part II).

Roes, A. W. M. and yan Swaaij, W. P. M., 1979a, Axial dispersion of gas and solid phases in a gas-solid packed column at trickle flow. Chem. Engng $J$. 18, 13-28.

Roes, A. W. M. and van Swaaij, W. P. M., 1979b, Mass transfer in a gas-solid packed column at trickle flow. Chem. Engng J. 18, 29-37.

Verver, A. B. and van Swaaij, W. P. M., 1986a, The hydrodynamic behaviour of gas-solid trickle flow over a regularly stacked packing. Powder Technol. 45, 119-132.

Verver, A. B. and van Swaaij, W. P. M., 1986b, The heattransfer performance of gas-solid trickle flow over regularly stacked packings. Powder Technol. 45, 133-144.

Verver, A. B. and van Swaaij, W. P. M., 1987, The gas-solid trickle-flow reactor for the catalytic oxidation of hydrogen sulphide: a trickle-phase model. Chem. Engng Sci. 42, 435-445. 